\title{
The complementary niches of anthropocentric and biocentric conservationists
}

MALCOLM L. HUNTER JR., * KENT H. REDFORD

*Department of Wildlife Ecology, University of Maine, Orono, ME 04469, USA, email mhunter@maine.edu †Archipelago Consulting, PO Box 4750, Portland, ME 04112, USA

$\S$ Fenner School of Environment and Society and Australian Research Council Centre of Excellence for Environmental Decisions, The Australian National University, Canberra, ACT 0200, Australia

Running head: Anthropocentrists and biocentrists

Keywords: anthropocentric, biocentric, ecosystem services, extinction, meta-analysis, values

\section{Abstract}

A divergence of values has become apparent in recent debates between conservationists who focus on ecosystem services that can improve human well-being and those who focus on avoiding the extinction of species. These divergent points of view fall along a continuum from anthropocentric to biocentric values, but most conservationists are relatively closer to each other than to the ends of the spectrum. We have some concerns with both positions but emphasize that conservation for both people and all other species will be most effective if conservationists focus on articulating the values they all share, being respectful of divergent values, and collaborating on common interests. The conservation arena is large enough to accommodate many people and organizations whose diverse values lead them to different niches that can, with good will and foresight, be far more complementary than competitive.

\section{Introduction}

Skepticism and debate are hallmarks of vigorous science, but in conservation science we also must contend with differences in the values that underlie conservation goals. Recently, these differences have surfaced in the pages of Conservation Biology with Michael Soule's editorial criticizing "new conservation" and responses (Soule 2013; also see Kareiva et al. 2012; Kareiva \& Marvier 2012; Doak et al. 2013; Cafaro \& Primack 2014; Kareiva 2014 [this issue]; Marvier 2014; Soule 2014 [this issue]). This exchange brings to the fore the fact that conservationists often argue about their practices without discussing the values underlying their positions (e.g., Callicott 1990). Here we consider the continuum from anthropocentrism to biocentrism and what it means for conservation practice (Meine 2004). At one end of the continuum, people who are strongly anthropocentric care only about the welfare of humanity; all 
other species are resources to be exploited. They would be content in a world dominated by domestic species as long as there was sufficient food, water, and oxygen and whatever other elements of nature are necessary to provide people with healthy, happy lives. Conversely, people who are strongly biocentric consider Homo sapiens no more intrinsically important than any other species. Because of the overwhelming threats people pose to other species, biocentrists would prefer a world with a far lower human population living lifestyles that greatly reduced humanity's impact on wild species, even if it compromised their material well-being.

By describing these furthermost ends of the continuum, it becomes apparent that Soule leans toward the biocentric pole while Kareiva and Marvier are closer to the anthropocentric pole, but that they are much closer to one another than to either of the poles. Indeed, we believe their niches within the conservation movement are close and complementary, which should not be surprising given that they all explicitly say they value biodiversity. We begin by distilling the opinions expressed by these writers, characterizing them collectively as the anthropocentrists and the biocentrists. We emphasize that these writers only trend toward different ends of the values continuum and that we are trying to present fair portraits, not caricatures. In presenting these characterizations we also share some of our concerns related to their differences. We focus on the arguments that have been presented to the readers of Conservation Biology even though they have a fairly strong North American-centric perspective, reflecting conservation as it has unfolded on a continent that still harbors large areas of uninhabited land (in sharp contrast to Europe and most of Asia). Similarly, conservation is shaped by the economic well-being of its inhabitants, and in this respect the U.S. and Canada are different from many developing countries.

\section{Anthropocentric conservationists}

To place Kareiva and Marvier on the anthropocentric-biocentric continuum requires some triangulation. On the one hand, some of their statements are clearly anthropocentric; for example, "For me at least, the rights of people for self-determination take supremacy over any species or biodiversity tally. It is my job as a conservation scientist to find the ways that people can indeed come first and while biodiversity can also be protected" (Kareiva 2009). On the other hand, they indicate that existence values constitute an ecosystem service and thus as long as people know about a particular species and value its existence, then it merits conservation (Marvier 2014). Taken in aggregate they are certainly more anthropocentric than Soule, and based on at least one of their papers (Kareiva et al. 2012), they may well be more anthropocentric than most conservation biologists. Regardless of their exact priorities, Kareiva and Marvier's goal of achieving more biodiversity conservation by expanding the constituency for conservation is certainly an attractive idea that we support. We also agree that a key way to accomplish this is to seek approaches to conservation that generate outcomes that benefit both people and nature (see Turner et al. 2012). This is certainly not a new endeavor; it has long been the basis for conservation in Europe and has also been central to North American conservation for over a century (Leopold 1931).

We are concerned, however, that the anthropocentrists seem to embrace the viewpoint of some ecosystem ecologists who focus almost entirely on the emergent properties of ecosystems such as productivity and stability. This position minimizes the perspective of ecologists and 
evolutionary biologists who focus on species, especially the rates of local extirpations and global extinctions. Both ecosystem-focused and species-focused activities certainly have a role in conservation (Likens \& Lindenmayer 2012). However, there is an important distinction: many highly degraded ecosystems can recover, at least partially, from disturbance, sometimes in a surprisingly short period, but species do not recover from extinction. The anthropocentrists' anecdote about the loss of American chestnuts (Castanea americana) from the forests of eastern North America is illustrative (Kareiva et al. 2012). They emphasize the apparent resilience of the forest ecosystem rather than the loss of a species that was of great value as a source of timber and other goods for people and as a food source for many species. This leads to a related concern.

Anthropocentrists put enormous emphasis on instrumental values, which they generically call ecosystem services thus emphasizing the link to ecosystem processes. This inevitably diminishes the importance of species with less instrumental value, such as the half dozen or so species of moths associated with chestnut forests that are now extinct (Orwig 2002). This is problematic for biocentrists who believe all species have intrinsic value. The idea of intrinsic value is challenging for some ethicists (Justus et al. 2009), but it is firmly embraced in both scientific and policy circles, including by the people who put intrinsic value in the very first words of the Convention on Biological Diversity (http://www.cbd.int/convention/text/default.shtml): "The Contracting Parties, conscious of the intrinsic value of biological diversity ..." Similarly, if one focuses strongly on demonstrable instrumental values, the idea of potential value - the not-yet-realized or not-yet- known value biodiversity may have to future generations - would have relatively less weight (Ibrahim et al. 2013).

We are also concerned that strongly emphasizing conservation activities that generate major gains for people necessarily may mean concentrating efforts in places near people, with little activity focused on remote areas ( $>100 \mathrm{~km}$ from population centers), where there are considerable opportunities for high biodiversity gains at relatively low cost. With important exceptions including carbon sequestration projects, which can help manage global atmospheric carbon wherever they are located, provision of most ecosystem services may often be more efficient if located relatively close to population centers. For example, the classic model of ecosystem services, protecting watersheds to assure clean, abundant water for human use, will usually not generate conservation activity far beyond the nearest city or agricultural region. This issue is particularly worrisome because the constraints on conservation activity (e.g., land prices) are often much greater where population densities are higher. Imagine choosing between investing a fixed sum of money in a 1000 ha watershed close to a city of a million people versus using that money to conserve a 10,000 ha watershed where only a few hundred people live. All other things being equal, biocentrists would surely choose the larger, remote watershed, but anthropocentrists would usually choose the one where more people would benefit. They believe that by choosing the urban watershed, the conservation community can move beyond a zero sum game by enlisting new supporters (notably water utilities in this case). There is some evidence to support this as measured by funding sources (Goldman et al. 2008).

We are also dismayed by anthropocentrists who anger many traditional supporters of conservation (conservation professionals, outdoor enthusiasts, naturalists, and philanthropists) by 
criticizing iconic ideas in some of their writings, notably the importance of setting aside reserves (Kareiva et al. 2012). While we acknowledge that the creation of reserves has sometimes had negative outcomes for local people, this issue is being addressed (Springer et al. 2010). Anthropocentrists also have criticized attempts to control invasive exotics; they celebrate "rambunctious gardens" rather than seeing novel ecosystems, however inevitable, as examples of biological and cultural loss (Marris 2011). We are not opposed to examining traditional strategies in the light of new data and insights, but if the anthropocentrists were more diplomatic they could challenge conventional thinking without evoking such strong reactions.

\section{Biocentric conservationists}

Soule is well known among conservation biologists, in part because of his eloquent writing: "Is the sacrifice of ...natural productivity, beauty, and diversity prudent, even if some human communities and companies might be enriched? No. The worth of nature is beyond question and our obligation to minimize its gratuitous degradation is no less" (Soule 2013). To understand Soule's biocentric nature and his criticism of Kareiva and Marvier's so-called new conservation one needs to realize that his definition of conservation differs from the word's earliest roots in a natural resource context. When the forester Gifford Pinchot imported the word from food science, the key idea was to carefully manage natural resources for the equitable benefit of many people, including future generations (Callicott 1990). For Soule, conservation is first and foremost about preserving biodiversity, especially species endangered with extinction, and the main tool for this is establishing reserves. We strongly agree that careful management of endangered species and ecosystems is often best done by preserving them in reserves, but conservation for many species and ecosystems may involve carefully using them for human benefit.

Some prominent biocentrists offer a bold vision, a planet in which at least $50 \%$ of the land area is devoted to wild nature (Noss et al. 2012; also see Caro et al. 2012). We, however, think it is unrealistic to expect to create such a world given the growing population of people, most of whom aspire to greater levels of consumption, and the pervasive global impacts of human activity (Rockstrom et al. 2009). More importantly, we are concerned that advocates for such scenarios will be marginalized as misanthropic. Fifty percent or more may be achievable in some parts of the world (such as western North America and the marine, polar, and boreal realms [McCauley et al. 2013]), but it seems highly improbable in most of Asia and Europe and significant parts of Africa, Australia, and the Americas. Perhaps advocating such a high percentage has some heuristic value, but if it damages the credibility of conservation scientists, what will have been accomplished?

While we were glad that Soule brought these issues to the pages of Conservation Biology, we were concerned that he called out a few U.S.-based organizations, most conspicuously The Nature Conservancy, among the many organizations (e.g., Conservation International and the International Union for the Conservation of Nature) that have placed more emphasis on ecosystem services in recent years. We believe it would have been preferable to respond to Kareiva and Marvier's provocative ideas in a manner that did not diminish the public reputation of any of the world's biodiversity conservation organizations. 


\section{The role of science}

Both the anthropocentrists and the biocentrists challenge each other's interpretation of the science underlying conservation, but it is important to realize that they are arguing about what broad lessons for conservation can be derived from science. Whatever the outcome of such arguments, we are somewhat concerned that such debates increase the temptation to extrapolate from generic scientific results to specific conservation decisions (see Jones \& Schmitz [2009] cited by Kareiva et al. [2012]; also see Whittaker 2010). For example, imagine a compilation of studies on the efficacy of fish lifts at dams that indicated that $\mathrm{X} \%$ of fish lifts allow $\mathrm{Y} \%$ of migratory fish species to remain within the natural range of variability of their pre-dam population levels. Would that overarching information really be central to the decision to dam a particular river, especially if one of those fish species is threatened with extinction and the percentage of successful lifts is below $95 \%$ or some other comfort level? How large a risk of extinction or a major decline should decision makers accept? Claims from both poles (e.g., "I like the odds so let's roll the dice." vs. "Any risk is too great.") are extreme and impractical for decision making (Salafsky \& Redford 2013). And of course the role of scientists is only estimating risk; decision makers will decide what is acceptable. Finally, while we certainly support scientific research, including meta-analyses, we do not think that arguments about interpretation of science can resolve arguments over values (Burgman \& Lindenmayer 1998).

\section{Respect and Collaboration}

The conservation community is made up of an ever-changing mix of individuals with diverse values and has increasingly brought into its fold people from different backgrounds, including economics, policy, and public health. Some lean toward biocentrism, some toward anthropocentrism, some are comfortable as centrists, and many change as their experiences and perspectives evolve, often becoming more inclusive. Conservation organizations themselves match this mix with values that vary widely, from Greenpeace, with its stronger biocentrism, to the United Nations Development Program (UNDP), with its stronger anthropocentrism, for example. Some organizations have distinct niches defined, in part, by their place on the anthropocentric to biocentric continuum: certainly there would be little overlap between the often confrontational tactics of Greenpeace and the sustainable forestry programs of UNDP. Other groups, especially larger ones like The Nature Conservancy and Worldwide Fund for Nature, have a diverse portfolio of activities driven by a wide spectrum of values. And like individuals, groups can also change their values and strategies over time. All of this plays out in the context of particular conservation problems, and these vary enormously both spatially (among ecosystems, regions, and nations) and temporally (consider the advent of the climate-change issue). Whenever, wherever it is undertaken, conservation for both people and all other species will be most effective if we focus on articulating the values we share, being respectful of divergent values, and collaborating on common interests. The conservation arena is large enough to accommodate many people and organizations whose diverse values lead them to different niches that can, with good will and foresight, be far more complementary than competitive.

\section{Acknowledgments}


We received thoughtful reviews of earlier drafts from T. Barron, M. Burget, A. Calhoun, R. Knight, M. Marvier, T. McClanahan, C. Meine, H. Possingham, M. Scott, M. Tetreault, S. Trombulak, W. Turner, B. Vickery, D. Wilcove, and three anonymous reviewers. This is Maine Agricultural and Forest Experiment Station Publication No 3364.

\section{Literature Cited}

Burgman, M. and D. Lindenmayer.1998. Conservation biology for the Australian environment. Surrey Beatty and Sons, Chipping Norton, New South Wales.

Cafaro, P. and R. Primack. 2014. Species extinction is a great moral wrong. Biological Conservation 170:1-2.

Callicott, J.B. Whither conservation ethics? Conservation Biology 4:15-20.

Caro, T., J. Darwin, T. Forrester, C. Ledoux-Bloom, and C. Wells. 2012. Conservation in the Anthropocene. Conservation Biology 26:185-188.

Doak, D.F., V.J. Bakker, B.E. Goldstein, and B.Hale. 2013. What is the future of conservation? Trends in Ecology \& Evolution DOI: 10.1016/j.tree.2013.10.013.

Goldman, R.L, H. Tallis, P.Kareiva, and G.C. Daily. 2008. Field evidence that ecosystem service projects support biodiversity and diversify options. Proceedings of the National Academy of Sciences 105:9445-9448.

Ibrahim, M.A. M. Na, J. Oh, R.F. Schinazi, T.R. McBrayer, T. Whitaker, R.J. Doerksen, D.J. Newman, L.G. Zachos, M.T. Hamann. 2013. Significance of endangered and threatened plant natural products in the control of human disease. Proceedings of the National Academy of Sciences 110:16832-16837.

Jones, H. P., and O. J. Schmitz. 2009. Rapid recovery of damaged ecosystems. PloS ONE 4 DOI: 10.1371 /journal. pone.0005653 .

Justus, J., M. Colyvan, H. Regan, and L. Maguire. 2009. Buying into conservation: intrinsic versus instrumental value. Trends in Ecology \& Evolution 24:187-91.

Kareiva, P. 2009. Should protected areas be reexamined? Conservancy Talk blog. The Nature Conservancy, Arlington, Virginia. Available from

http://blog.nature.org/conservancy/2009/05/19/protected-areasmark-dowie-conservationrefugees-peter-kareiva/ (accessed December 2013).

Kareiva, P. 2014. New conservation: setting the record straight and finding common ground. Conservation Biology: in press. 
Kareiva, P. M. Marvier, and R. Lalasz. 2012. Conservation in the Anthropocene: beyond solitude and fragility. Breakthrough Journal 2: http://thebreakthrough.org/index.php/journal/pastissues/issue-2/ conservation-in-the-anthropocene/.

Kareiva, P., and M. Marvier. 2012. What is conservation science? BioScience 62:962-969.

Leopold, A. 1933. Game management. Scribner's, New York.

Likens, G. E., and D. B. Lindenmayer. 2012. Integrating approaches leads to more effective conservation of biodiversity. Biodiversity and Conservation 21:3323-3341.

Marris, E. 2011. Rambunctious garden. Bloomsbury, New York.

Marvier, M. 2014. New conservation is true conservation. Conservation Biology 28: 1-3.

Marvier, M., and P. Kareiva. 2014. The evidence and values underlying 'new conservation.' Trends in Ecology \& Evolution: in press.McCauley, D. J., E. A. Power, D. W. Bird, A. McInturff, R. B. Dunbar, W. H. Durham, F. Micheli, and H. S. Young. 2013. Conservation at the edges of the world. Biological Conservation 165:139-145.

Meine, C. 2004. Correction lines: essays on land, Leopold, and conservation. Island Press, Washington, D.C.

Noss, R. F. et al.. 2012. Bolder thinking for conservation. Conservation Biology 26:1-4.

Orwig, D. A. 2002. Ecosystem to regional impacts of introduced pests and pathogens : historical context, questions and issues. Journal of Biogeography 29:1471-1474.

Rockstrom, J. et al. 2009. A safe operating space for humanity. Nature 461:472-475.

Salafsky, N. and K.H. Redford. 2013. Defining the burden of proof in conservation. Biological Conservation 166:247-253.

Soule, M. 2013. The "new conservation.” Conservation Biology 27:895-897.

Soule, M. 2014. Also seeking common ground and seeking to dispel misimpressions. Conservation Biology: in press.

Springer, J., J. Gastelumendi, G. Oviedo, K. W. Painemilla, M. Painter, K. Seesink, H. Schneider, and D. Thomas. 2010. The Conservation Initiative on Human Rights : promoting increased integration of human rights in conservation. Policy Matters 17:81-83.

Turner, W. R., K. Brandon, T. M. Brooks, C. Gascon, H. K. Gibbs, K. S. Lawrence, R. A. Mittermeier, and E. R. Selig. 2012. Global biodiversity conservation and the alleviation of poverty. BioScience 62:85-92. 
Whittaker, R. J. 2010. Meta-analyses and mega-mistakes: calling time on meta-anlysis of the species richness-productivity relationship. Ecology 91:2522-2533. 